\title{
Relationship between Social Media Collaboration and Ecosystem Management in Enugu State, Nigeria
}

\author{
Emmanuel. K. Agbaeze ${ }^{1}$, Ajoku P.P Onyinye ${ }^{1}$, Obamen Joseph ${ }^{1}$, Omonona Solomon ${ }^{2 *}$ \\ ${ }^{1}$ Business Management department, University of Nigeria, Enugu Campus, Nigeria \\ ${ }^{2}$ Business Management department, University of Fort Hare, Eastern Cape, South Africa \\ 201716526@ufh.ac.za, Omononamise@gmail.com*
}

\begin{abstract}
This study was done on the relationship between social media collaborations and ecosystem management in Enugu state. The study was premised on the case of herdsmen-farmers/villagers clash over grazing fields and farmlands in Enugu State being the ecology-related issue. Survey research design was adopted for the study. A sample of 100 social media group participants was selected using snowball sampling technique. The questionnaire was used for data collection. Content validity was used as a method for testing the validity of the questionnaire while Cronbach's alpha method was used for testing the internal consistency of the items on the questionnaire. Pearson's Product Moment Correlation was used to test the hypothesis formulated for the study. Findings revealed that social media collaborations via Facebook, WhatsApp and Twitter have a significant relationship with ecosystem management. It was recommended that government and ecologically concerned agencies should employ social media collaborations as the policy for ecosystem management.
\end{abstract}

Keywords: Social Media, Social Media Collaboration, Ecosystem Management

\section{Introduction}

Shortly after the emergence of internet usage in Nigeria, social media gained an earth-shaking wave of subscribers in the country with people starting to admire staying online, wanting to share information and communicate with one another through the then desktop computers accessed through Internet Cafes in the neighbourhoods. Yahoo mail, Yahoo messenger, Hotmail and Ask.com were the commonest social media app existing as at then but today, scores of social media networks and applications have sprung up ranging from Facebook, WhatsApp, 2go, YouTube, Twitter, LinkedIn, Snap chat etc. Internet-enabled mobile smartphones and portable browsing gadgets like Tablets that are recently introduced also contributed to this enormous growth in the social media usage. It all began in the early days of Blackberry messenger which connected users in intertwines of social networks or community-based networks using PINs. Apple too was in the game of bringing people into a closed circuit of the social network through its own iPad, iphone, iTunes, etc. The unfortunate part of these miniature developments was that, the social network was restricted only to users of the mobile gadget carriers of the network which were very expensive. However, the arrival of Android Jelly Bean application brought billions of people in the world to the light of social networks. Today, nearly all users of smartphones are now subscribers to one social media platform or the other (especially Facebook and WhatsApp) with the aid of the Android operating system.

With the continued growth in social media networks, collaboration started to emerge as users of the social media are able to form groups on their networks, chat together, share contents and relate with one another even to as many people as possible at a time unlike when it was one on one connection (Meredith, 2014). Through group chats, information about anything or occurrences travels at the speed of light across the networks and from persons to persons. For believability, contents too are shared both in the picture or video formats. This development further attracts huge research concerns because it continues to shrink the world into a complex web of networks thereby providing collaborative information access for users and group participants (Tamine, 2016). Therefore, as part of the socializing features of the networks, scores of researchers have spotted the collaborative functional roles of social media networks for managing ecologically related issues. In the Western United States, one extant study captured how social media collaborations could be used to manage four (4) ecologically related issues (Keough, and Blahna, 2005). Another extant study from the central Stockholm County, Sweden, was done to show how web-based collaborations among 25 municipalities related to the management of 408 wetlands across the county (Kininmonth, and Bergsten, 2015). In actual fact, extant studies make it known that ecological resources are not independent of each other, instead they are interconnected, and their well-being is often critically dependent on upholding ecological connectivity, especially in times of change and disturbances. 
Therefore, coordination and collaboration among managing actors, each managing their own piece of the puzzle, is essentially a requirement for effective management (Kininmonth, and Bergsten, 2015). Building on this, a growing number of ecosystem-related issues are discussed on a regular basis via the social media networks by group members. Similar to the case of Malpai Borderlands Group (ecoregional rangemanagement issue) reported in Keough and Blahna's (2005) study, in almost all parts of Nigeria today, there have been serious conflicts between the herdsmen and farmers arising due to the declining grazing fields for cattle consequent to the widening development in human ecology. Now, using the cattle grazing fields that are now increasingly converted to farmlands and for human settlements as the ecological resource, this has become a trendy topical issue discussed on the social media groups. As the only available option for the herdsmen, they want to feed their livestock (cattle) on farmers' cultivated land but in retribution, this results in serial killings. Take for instance in Nsukka, Enugu state alone, about seven villages (Nimbo, Ngwoko, Ugwuijoro, Ekwuru, Ebor, Enugu Nimbo, Umuome and Ugwuachara) were attacked by the herdsmen leaving scores of lives in a bloodbath. Despite the increasing research efforts on the connectivity between social media collaborations and ecosystem contextual managements, one growing concern bothers on how the collaboration is done on social media networks which eventually can lead to ecosystem management considering the fact that most groups on social media networks are set up for education, politics, football and several other affairs.

Some restrict posting of irrelevant messages but on groups like 'Old Students Classmates', informal posts which may include ecosystem related issues are allowed. In addition, while this actually forms the basis this current study, some proponents argue that collaboration pattern on social media networks goes beyond public involvement, and before decisions relating to how well ecosystem resources are managed, inclusiveness, interactions, and joint decision making through consensus-based approaches are such collaborative frameworks required for ecosystem resource management (Walker and Daniels, 1996; Gray, 1989). Moreover, considering also that such social media group does not include one participant dominating (at the expense) over others (Keough, and Blahna, 2005). Building upon this premise, however this study will be of immense benefit to humanities and of course the people of Enugu state in particular because of it X-ray and proffer solutions to the herdsmen-farmers/villagers clash over grazing fields and farmlands in the region, through the use of social media collaboration. While it seeks to assess the relationship between social media collaborations and ecosystem management utilizing the participation in Facebook group chats, WhatsApp group chats, Twitter group chats and Linked in group chat as variables to the management of herdsmen farmers' conflict in Enugu, Nigeria.

Statement of the Problem: Social media networks are internet enabled websites and applications that allow users to create and share content. They exist in two versions - desktop and mobile versions. Most commonly in Nigeria, these include Facebook, WhatsApp, 2go, Twitter, LinkedIn, YouTube, etc. Not only are these media used for social networking, users now use them for diverse collaborating functions because it allows for groups creation, group chats, and group information and content sharing. Some use it as a platform for education while some use it for social bonding. In the light of these, there has been a growing academic research concern on the governance of interactions via these social media groups (Kemmis, 1990) because, in some groups, members would just post any unruly information that is not educative on the platform (especially for those groups that were set-up purposely for education collaboration) but, as for groups that were set-up freely among friends for social bonding collaborations, anecdotal evidence provides that members barely make any serious discussion on the platform not to talk of debating or deliberating over ecosystem management related issues.

Among extant studies, there seem to be some mixed results regarding this collaborating function of social media and ecosystem management issue. Some studies like Rathwell and Peterson (2012) argue that the municipalities of Montreal, Quebec, Canada do not collaborate directly with one another over the watershed governance and water quality management issue that caused conflicts between amenity and agricultural activities whereas, in studies like Kininmonth and Bergsten (2015), it is argued that there is a good social and ecological alignment i.e. there is a governed structure that align collaborations to ecological processes among 25 municipalities which help to manage 408 wetlands in central Sweden. Meanwhile, of all the studies carried out in the past, there is still a paucity of this type of research study in Nigeria. Now, presenting the herdsmen/farmers or villagers' clash in Enugu communities over the grazing field and farmlands as pressing 
the ecological issue in this study, it becomes worrisome to empirically address whether the various collaborations on social media groups today are focused or directed toward managing ecosystem related issues at all.

Objective of the Study: The main objective of this study is to assess the relationship between social media collaborations and ecosystem management. The specific objective therefore includes;

- To determine the relationship between the use/participation in Facebook group chats and management of herdsmen-farmers conflicts in Enugu state, Nigeria.

- To determine the relationship between the use/participation in WhatsApp group chats and management of herdsmen-farmers conflicts in Enugu state, Nigeria.

- To determine the relationship between the use/participation in Twitter group chats and management of herdsmen-farmers conflicts in Enugu state, Nigeria.

- To determine the relationship between the use/participation in LinkedIn group chats and management of herdsmen-farmers conflicts in Enugu state, Nigeria.

Research Questions: What is the relationship between using social media and management of herdsmenfarmers' conflicts in Enugu state, Nigeria.

\section{Research Hypothesis}

$\mathrm{H}_{1}$ : There is a significant relationship between using Facebook group chats for collaboration and management of herdsmen-farmers' conflicts in Enugu state, Nigeria.

$\mathrm{H}_{2}$ : There is a significant relationship between using of WhatsApp group chats for collaboration and management of herdsmen-farmers' conflicts in Enugu state, Nigeria.

$\mathrm{H}_{3}$ : There is a significant relationship between using Twitter group chats for collaboration and management of herdsmen-farmers' conflicts in Enugu state, Nigeria.

$\mathrm{H}_{04}$ : There is no significant relationship between using of LinkedIn group chats for collaboration and management of herdsmen-farmers' conflicts in Enugu state, Nigeria.

\section{Literature Review}

Conceptualizations: The concepts of social media and ecosystem management have been used widely in diverse contemporary discourses, but here in this study, the emphasis is on the connectivity between two terms - i.e. social media collaboration and ecosystem management.

\section{Figure 1: Social Network}

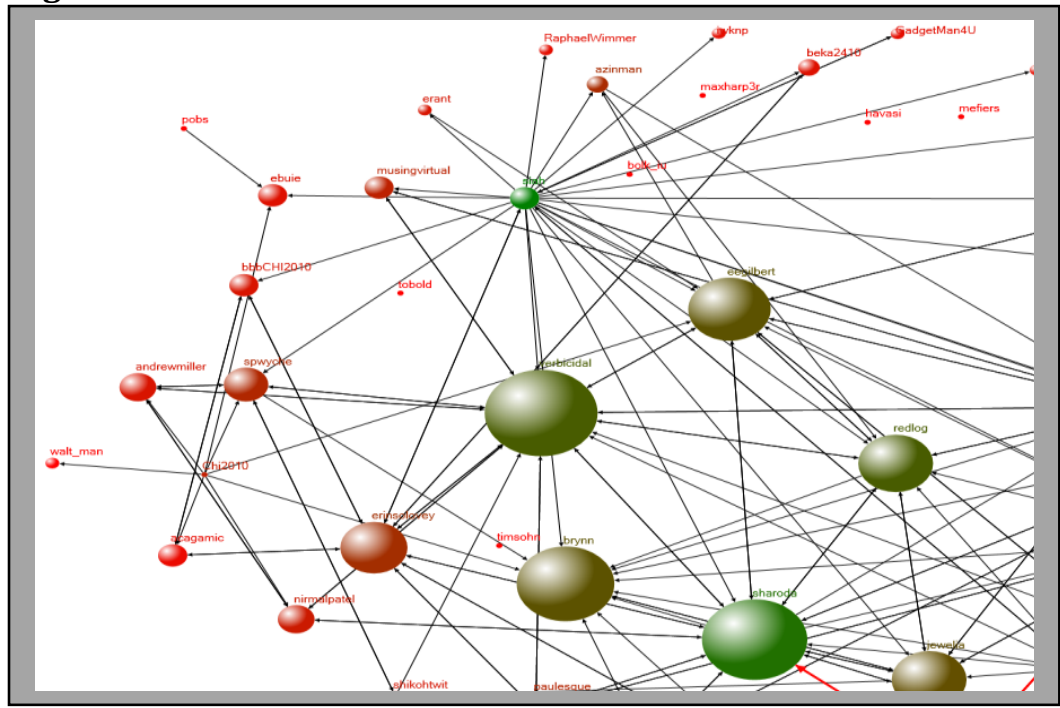

Source: Dolwick, J.S. (2009). 
Social Media Collaboration: The term Social Media comprises of two separate concepts; social and media. Jointly defined, it refers simply to the means or medium through which members of a society intermingle. Generally, social media is described as a set of online communication channels. It is an online community dedicated for social interaction, sharing of pleasantries, all manner of social contents and ultimately for collaboration. From the meaning of 'social media' given above, the term Social Network can be meaningfully inferred as an internet-based services that allow individuals to (i) construct a public or semi-public profile within a bounded system, (ii) articulate a list of users with whom they share a connection, and (iii) view and traverse their list of connections and those made by others within the system. The nature and nomenclature of these connections may vary from site to site. While the term "Social Network Site" appears to have been widely employed to describe this emerging phenomenon (Tang et al., 2012; Baden et al., 2009), it also appears in most public discourses, and the two terms: Social Network Site and Social Networking Site seem to be often used interchangeably. Here in this study, the term network suffixing 'social media' would be employed and not "networking" simply for two reasons: emphasis and scope. "Networking" emphasizes relationship initiation, often between strangers and while it may be possible on some sites, it might not be the primary purpose of many of others, nor is it what differentiates them from other forms of computer-mediated communication (CMC) (Dolwick, 2009).

What makes social network sites unique is not only that they allow individuals to meet strangers as demonstrated on Figure 1 above, but rather that they enable users to articulate and make visible their social networks. This can result in connections between individuals that would not otherwise have been made, but that is often not the primary goal, and these meetings are frequently between "latent ties" (Haythornthwaite, 2005) who share some offline connection. Meanwhile, on many of the large social network sites [SNSs], many participants are not necessarily "networking" or looking to meet new people; instead, they are primarily communicating with people who are already a part of their extended social network (Keitzmann and Kristopher, 2011). Having described the term 'social media network', the concept of social media collaboration therefore, can be drawn from the intertwining relationship between people on the networks.

Carr and Ebrary (2014) define social media collaboration as the processes of bringing groups of people together to interact and share information in order to achieve common goals. This process presents the 'natural' environment on the internet, where collaboration and social dissemination of information are made easier through current innovations through social networks like WhatsApp, 2go, Facebook, LinkedIn, Twitter, etc. Oftentimes, the information sharing feature of groups on social media networks facilitates "brainstorming" because new ideas emerge from time to time due to the varied contributions of the participants. The participants come from different spheres of life, different cultures and different age groups. One crucial concept behind social media collaboration is that ideas flow every angle and from persons to persons across groups. Individuals are able to share their ideas in an unrestricted environment as anyone can get involved and the discussion is not limited to only those who have domain knowledge.

Ecosystem and Ecosystem Management: The term 'ecosystem' refers simply to the house (environments) of all living things. It is the biological community of all lives whether animals or plants (TEEB, 2010). The term also refers to 'Ecology' which is the study of the ecosystem. It refers to the geographical space where all living things live and interact with one another. For clarity purpose, ecosystem refers to all living things interacting with one another and with the environments - the water, soil, weather, climate and the sun including the atmosphere. In the context of this current study, ecosystem refers to the interaction between humans (herdsmen and farmers), cattle and the environment (the grazing fields). The grazing fields are bush (fertile lands or undeveloped lands). They represent the environment while the cattle, herdsmen and the indigenes of Enugu state, Nigeria whose villages were enraged are the living things. Therefore, the interaction between these and the environment is the ecosystem referred to in this study. In the past, there was a vast area of undeveloped lands across Nigeria - no farmlands, no buildings, and no village settlements.

The herdsmen roam about with their cattle to feed them with grasses on these undeveloped lands. As time went on, developments in human ecology expanded with farmlands and village settlements replacing the vast area of undeveloped lands which the cattle were once fed on. This then leaves the herdsmen with no option but to feed the cattle with the crops on the cultivated lands hence, degenerating to bloody conflicts. Now, the concept of ecosystem management is defined as the process of conserving and restoring the natural resources 
yet meeting the needs of the current and future generations of living things (World Bank, 2009). Blending this definitive meaning to the context of this study, it, therefore, refers to the process conserving the ecological resources (human lives, cattle, and the lands) thereby managing the conflict between the herdsmen and the farmers or indigenes of the attacked villages. To achieve this, increasing development in human ecology (settlements) would be curtailed,and the wandering rate of the herdsmen and their cattle would also be curtailed.

Figure 2: Research Model

\section{Factors Aiding Ecosystem \\ Management through Social media Collaboration}

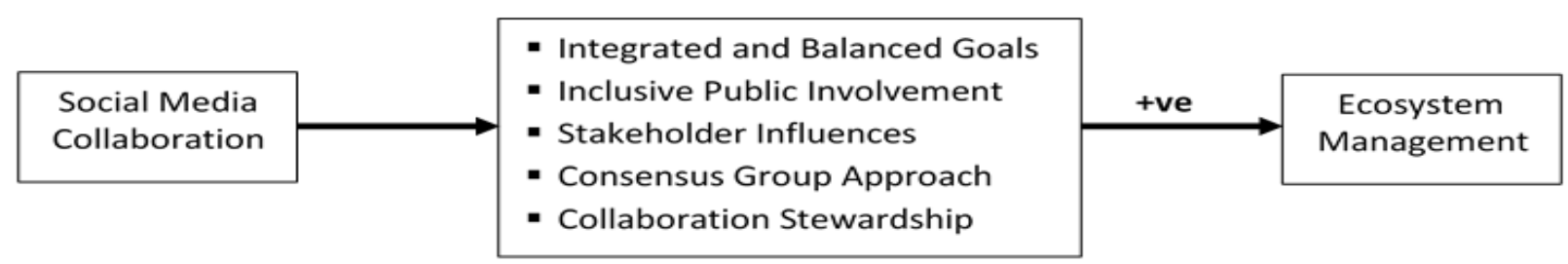

Fig. 1: Research Model

Source: Researcher's Intuitive Illustration

Figure 2 above represents the research model guiding this current study. The model (especially the factors aiding ecosystem management) is adapted from Keough and Blahna (2005). This model is proposed for the study of the relationship between social media collaboration processes and the management of herdsmen/farmers clashes over grazing fields and farmlands - which is the ecosystem in the context of this study. From the model, it is proposed that, if social media collaborations (topical issues discussed) are organized to conform to the five (5) ecosystem management aiding factors, this will lead to a positive relationship with the ecosystem management.

Empirical Reviews: Quite a number of studies have been done in the past on how social media collaborations can be used to manage ecosystem related issues, For instance, Keough and Blahna (2005) did a study titled Achieving Integrative, Collaborative Ecosystem Management, and focused on four cases relating to ecological management issues from the Western United States including - the Malpai Borderlands Group (ecoregional range-management issue); the Red Cliffs Desert Reserve (landscape -level endangered species issue); Maguire's primrose protection in Logan Canyon (landscape-level recreation and threatened plant conflict), and lastly, protecting the Moab Sand Flats (site- and landscape-level recreation and vegetation management issue). Findings revealed that creating an integrated balance between socioeconomic, and ecological goals can be possible so far one participant in the social media collaborating group does not dominate at the expense of the others. Another similar extant study is Kininmonth and Bergsten (2015) titled closing the collaborative gap: Aligning social and ecological connectivity for better management of interconnected wetlands. The study sought to understand how governance structures align to ecological processes in a landscape which is essential for effective management of ecological resources.

Findings showed a good social and ecological alignment however with a high prevalence of coordination through third parties. Olsson et al. (2003) also studied Social Networks for Ecosystem Management: A Case Study of Kristianstads Vattenrike, Sweden using the case study of Kristianstad's Wetland in Vattenrike, Sweden. The conclusion drawn from the study was that social networks play a crucial role in the dynamic relationship between key individuals, social memory, and resilience. They operate with a range of actors at different levels of society and create nodes of expertise and a diversity of experiences and ideas for solving new problems. Another similar extant study is Tamine et al. (2016) titled Social Media-Based Collaborative Information Access: Analysis of Online Crisis-Related Twitter Conversations. The study sought to better understand either implicit or explicit collaboration by studying Twitter, one of the most popular and widely used social networks. Findings showed that there is massive critical collaboration and is limited to smallsized flat networks, with or without an influential user; users are active as members of weakly overlapping 
groups and engage in numerous collaborative search and sharing tasks dealing with different topics; and lastly, collaborative group ties evolve within the time-span of conversations.

Gaps: From the reviewed extant studies, it is deduced that there is a paucity of similar research studies in Nigerian contexts. It does not mean that no ecological issues are happening around Nigerian environments. Several kinds exist out of which the herdsmen and farmers' clash over grazing fields and farmlands is one. Another identified gap from extant studies is from the scope covered. Fewer or no studies were extensive to capture Facebook, WhatsApp, 2go, LinkedIn, and YouTube which are common with Nigerians. Only Tamine et al. (2016) was able captured Twitter social media groups, and this study was not carried out in Nigeria.

Theoretical Framework: The concepts of social media collaboration and ecosystem management have been extensively conceptualized in the preceding section. In discussing the theoretical link between the two concepts, some theoretical approaches have been suggested in the past studies. For instance, as cited in Keough and Blahna (2005), Lee (1993) describes ecosystem management as a trade-off activity for easing the heat and tension created by the key actors (herdsmen and the farmers/indigenes) in the conflict by balancing the competing needs of these key actors over the land through democratic process. Meff et al. (2002) adopt the concept of integration for decision-making towards balancing ecological and socioeconomic factors. To them, they believe ecosystem management must be brought to the institutional context where managers, politicians, doctors, teachers, security, etc. should strive for win-win partnerships through collaborative approaches. Kininmonth and Bergsten (2015) adopt the common-pool resource theory which is about the natural resource sharing dilemma. To adapt these theoretical discourses to this present study, first, the competing need of the herdsmen and the farmers/indigenes is upon the land.

The herdsmen want to feed their cattle with the crops/grasses on the lands whereas the farmers/villagers/indigenes want to cultivate the lands for agricultural produces. Both actors seek commercial ends. Now, in balancing they're competing for their needs from the opinion of Lee (1993), Meff et al. (2002) suggest institutional integration for decision-making where managers, politicians, doctors, teachers, security, etc. including the aggrieved parties strive for win-win partnerships over the ecological resources through a collaborative approach. In this regard, it means that the conflict between the herdsmen and the farmers/villagers or indigenes in Enugu state over the ecological space can be resolved through a collaborative approach via the social media since the social media groups consist of participants who come from different spheres of life, different cultures, and different age groups. A growing research contention now is how the collaboration can be done efficiently to achieve management of the ecosystem that generates the conflict between herdsmen and the farmers/villagers. Keough and Blahna (2005) suggest eight (8) factors that are significant for achieving integrative and collaborative ecosystem management.

- Integrated and Balanced Goals

- Inclusive Public Involvement

- Stakeholder Influence

- Consensus Group Approach

- Collaborative Stewardship

- Monitoring and Adaptive Management

- Multidisciplinary Data

- Economic Incentives

In expatiating these eight factors, only the first five (5) factors are considered useful in this current study. They include; Integrated and Balanced Goals which refers to the bringing of herdsmen's goals and farmer's/villagers' goals to an agreeable point that is ecologically sustainable. The Inclusive Public Involvement refers to the bringing together of all concerned publics (Fulanis-Hausas, Igbos, and Yorubas) together in a social media group through which issues appertaining to the ensuing conflict is addressed. The Stakeholder Influence refers to the information input from each stakeholder and how impactful it is on the final decisions. The Consensus Group Approach refers to whether the social media group participants use a consensus-based approach for reaching an agreeable position or opinion. The Collaborative Stewardship 
refers to whether each participant has a sense of ownership for and become personally involved in the plan or decision reached

\section{Methodology}

Survey research design methodology was utilized for this study. The study was carried out in Enugu state, Nigeria specifically among lecturers, civil servants, and bankers including students all of whom are members of one social media group or the other. While the population of the subscribers remains infinite, the researchers captured a sample of 100 using both purposive and snowball sampling techniques. Data was collected using a questionnaire on a 5-point Likert scale. The questionnaire was validated using content validity method while Cronbach's alpha method was utilized for reliability/internal consistency. Pearson's Product Moment Correlation (PPMC) was used to test for the strength of the relationships that exist between variables.

Presentation of Results: Since the questionnaire copies were self-administered, 93 copies were supplied with complete data. Only seven copies could not be fully completed. Altogether, the survey had a success response rate of 93\%. Obot (2004) in Nwosu and Wilson (2004) notes that in resolving conflict in modern societies, the media, to a great extent, provide rendezvous for all the interest groups or the aggrieved parties to sit and express their minds on issues in contention. This would be possible by providing and guaranteeing every citizen, easy access to media facilities. Ndolo (2005) found out that the media gain insight into the circumstances of others, they identify with others and gain a sense of belonging, thus, and they are so useful in times of crisis. Through the collaborative functional roles of social media networks will help in managing ecologically related issues. Mass media facilitate the creation of meaningful communication between conflicting parties. It is infused with social responsibility and could provide tools and strategies to manage and process the rhythms, images, collective memories, fears and needs that shape positive perceptions about conflict management. The demographic data of the social media group participants are presented in table 1 below.

Table 1: Respondents' Demographic Data

\begin{tabular}{llllll}
\hline & Freq. & Percent & \multicolumn{2}{c}{ Freq. } & Percent \\
\hline Gender & & & \multicolumn{2}{l}{ Education Background } & \\
Male & 54 & $58.1 \%$ & None & 0 & $0.0 \%$ \\
Female & 39 & $41.9 \%$ & FSL Cert. & 0 & $0.0 \%$ \\
& 93 & $100.0 \%$ & O'Level & 8 & $8.6 \%$ \\
Yrs of Experience & & & NCE/OND & 21 & $22.6 \%$ \\
< 5years & 52 & $55.9 \%$ & BSc/HND & 19 & $20.4 \%$ \\
$5-$ yyears & 11 & $11.8 \%$ & Postgraduate & 45 & $48.4 \%$ \\
10 - 14years & 23 & $24.7 \%$ & & 93 & $100.0 \%$ \\
$\geq 10$ years & 7 & $7.5 \%$ & & & \\
& 93 & $100.0 \%$ & & & \\
\hline
\end{tabular}

Source: Field Study, 2018

Table 1 above presents the demographic data of the social media group participants who were captured in the survey for this study. The table shows the gender distribution, education background and years of experience in participating in the social media group. On gender distribution, 54(58.1\%) of them are males while $39(41.9 \%)$ others are females. On education background, 8(8.6\%) said they have 0'Level; $19(20.4 \%)$ said they have NCE/OND certificate while 21(22.6\%) said they have BSc/HND certificate and 45(48.4\%) others indicated that they hold postgraduate certificates. As for their years of experience in participating in social media groups, $52(55.9 \%)$ of them indicated that they have been participating in it for less than 5years; $11(11.8 \%)$ of them indicated 5 - 9years; $23(24.7 \%)$ of them indicated $10-14$ years while $7(7.5 \%)$ others indicated $\geq 15$ years.

Test of Hypotheses: To test the hypothesis, the data gathered on social media collaborations and ecosystem management in the context of herdsmen/farmers' clash over grazing lands and farmlands in Enugu state 
were subjected to test using Pearson's Product Moment Correlation method. The result of the test is presented in table 2 below.

Table 2: Pearson's Product Moment Correlation Test Result

\begin{tabular}{llllll}
\hline \multirow{2}{*}{ Ecosystem Management } & \multicolumn{2}{l}{ Social Media } & Collaborations through: & & \\
& Facebook & WhatsApp & 2go & Twitter & LinkedIn \\
\hline Integrated and Balanced Goals & $.887^{* *}$ & $.928^{* *}$ & .133 & $.451^{*}$ & .201 \\
& .000 & .001 & .129 & .000 & .093 \\
Inclusive Public Involvement & $.535^{* *}$ & $.771^{* *}$ & .294 & $.233^{*}$ & .139 \\
& .000 & .012 & .102 & .007 & .255 \\
Stakeholder Influences & $.813^{* *}$ & $.982^{* *}$ & .111 & $.601^{* *}$ & $.304^{*}$ \\
& .019 & .000 & .021 & .004 & .016 \\
Consensus Group Approach & $.662^{* *}$ & $.693^{* *}$ & .104 & $.644^{* *}$ & $.337^{*}$ \\
& .000 & .003 & .319 & .011 & .014 \\
Collaboration Stewardship & $.882^{* *}$ & $.545^{* *}$ & .217 & $.406^{*}$ & .116 \\
& .003 & .000 & .114 & .011 & .092 \\
\hline
\end{tabular}

${ }^{*}$ Correlation is significant at $5 \%,{ }^{* *}$ correlation is significant at $1 \%$

The result presented in Table 2 above represents the outcome of the Pearson's product moment correlation test. It can be deduced that collaborations via Facebook, WhatsApp, and Twitter have significant $(p<0.05)$ relationship with ecosystem management issues using the five (5) factors aiding the ecosystem management. 2go and LinkedIn have no significant $(p>0.05)$ relationship with ecosystem management. Based on this result, the null hypotheses $\left(\mathrm{H}_{1}, \mathrm{H}_{2}\right.$, and $\left.\mathrm{H}_{3}\right)$ would be rejected while their corresponding alternate hypotheses $\left(\mathrm{H}_{1}, \mathrm{H}_{2}\right.$, and $\left.\mathrm{H}_{3}\right)$ would be accepted but as for the remaining hypotheses, their null hypotheses $\left(\mathrm{H}_{04}\right.$ and $\left.\mathrm{H}_{05}\right)$ would be accepted while alternate hypotheses would be rejected.

\section{Findings and Discussion}

The findings can now be summarized as follows;

- There is a significant relationship between using Facebook group chats for collaboration and management of herdsmen-farmers' conflicts in Enugu state, Nigeria.

- There is a significant relationship between using of WhatsApp group chats for collaboration and management of herdsmen-farmers' conflicts in Enugu state, Nigeria.

- There is a significant relationship between using Twitter group chats for collaboration and management of herdsmen-farmers' conflicts in Enugu state, Nigeria.

- However,

- There is a significant relationship between using of LinkedIn group chats for collaboration and management of herdsmen-farmers' conflicts in Enugu state, Nigeria.

- There is a significant relationship between using of 2go group chats for collaboration and management of herdsmen-farmers' conflicts in Enugu state, Nigeria.

The above findings imply that Facebook, WhatsApp, and Twitter are the most widely used social media groups among the participants captured in Enugu state. Group discussions are sometimes directed toward any trendy ecological issues with particular reference to the recent herdsmen and farmers/villagers clash in Enugu villages. This result is consistent with Tamine et al. (2016) and Keough and Blahna (2006). The study also found out that there is a significant relationship between using of Facebook group chats for collaboration and management of herdsmen-farmers, a significant relationship between using of WhatsApp group chats for collaboration and management of herdsmen-farmers' conflicts and significant relationship between using of Twitter group chats for collaboration and management of herdsmen-farmers' conflicts in Enugu state, Nigeria. The findings align with Hoffmann (2013); Best (2013b) that social media enables people to engage in their initiatives for peace and allows for interactive dialogue. USIP (2011); Kelly and souter, (2014); Oatley (2011); Hoffmann (2013); Welch et al. (2013), Schoemaker (2014); Smyth and best (2013)and schoemaker (2013) found out that in some cases social media and other new media tools have been used to hold 
governments accountable to it citizens, mutually to protest violence, coordinate relief hard work, empower citizens, provide information to reduce tensions, and build bridges of understanding across boundaries.

In addition, Oatley (2011) Gagliardone et al. (2015) discover a positive but unreliable evidence that social media can contribute to peacebuilding by improving knowledge for conflict prevention and increasing contact and understanding between opposing groups. Welch (2015); Best (2013b); Smyth and Best (2013) states that Social media has been used to crowdsource information in conflict hotspots as part of various conflicts prevention measures in other countries like Kenya and Nigeria, especially during electioneering period. Social media has opened up new opportunities for public engagement and interactive dialogue and changed the relationship between government and citizens (Kelly and Souter, 2014; Best, 2013b; Schoemaker, 2014; Schoemaker, 2013). However, Pillay, van Niekerk, and Maharaj (2010); Coyle and Meier (2009) also establish that social media has proven to be a practical tool in advocacy and emergency communications. Mobile phones were a critical communications tool for social media in the aftermath of the 2004 Indian Ocean tsunami; this however was also the first time social media facility on mobile phones was used as a fund-raising tool. According to the study, social media also played a significant role in the aftermath of the 2011 Japanese earthquake and tsunami: more than 1,200 Twitter messages per hour were emanating from Tokyo within an hour of the earthquake (Vinson, 2011). Twitter was used to provide information on available shelters for stranded people and to raise funds (Vinson, 2011).

Ushahidi Community (2012) found out that Kenyan organization, Ushahidi developed free, open source platforms that crowdsource information during times of crisis. It operates with Twitter, mobile Short Message Service (SMS), and Google Maps was used successfully in many nations for both natural disasters and tracking political violence, including being used to track racist graffiti in the Middle East. Okoro and Diri (2009) found out that it is through the social media collaboration that the populace can participate freely in discussions relevant to their lives and their environment. It, therefore, implies that social media serves real tools that can be directed to headsmen management in south East-Nigeria. Individuals, groups, organizations, and nations are taking advantage of the opportunities provided by social media to organize millions of people to support and advance their course. In the political sphere, it has become a veritable tool for interacting and mobilizing citizens towards active contribution in the political process and democratic projects. The television, however, has greater political relevance, including the collection, organization, and transmission of news and information, the formation of opinion, and, in more or less open societies, some contribution to public debate (Ojo, 2003). The growing trend of social media surfing around the world extends to Enugu communities in Nigeria. Facebook, WhatsApp, and Twitter are the most widely used social media for group collaborations that can use to cub herdsmen-farmers' conflicts in Enugu state, Nigeria through quality reporting and collaboration of individual at all level.

\section{Conclusion}

This study sorts for the relationship between Social Media Collaboration and Ecosystem Management in Enugu State, Nigeria. However, herdsmen-farmers' clash knows as Fulani pastoralists migrating into Northern Nigeria from the Senegambia region around the thirteenth or fourteenth century (Adebayo, 1995; Abbass, 2001). After the Uthman dan Fodio jihad the Fulani became integrated into the Hausa culture of Northern Nigeria. After that, during the dry season, Fulani pastoralists began to drive their cattle into the middle belt zone dominated by non-Hausa groups returning to the north at the onset of the rainy season. However, while managing the herd and driving cattle, cattle grazing on farmlands sometimes occur leading to the decimation of yields and turning into a wellspring of contention. Nigeria's usage of the land utilizes act of 1978 permitted the state or federal government the privilege to allocate and rent arrive and furthermore gave indigenes the privilege to apply and be given an authentication of inhabitance to assert responsibility for genealogical terrains (Okello, 2014).

This put the pastoral Fulani in a troublesome position in light of the fact that most did not have any significant bearing for grounds of inhabitance of their brushing courses and repeating transhumance development will prompt infringement of the properties of others. The Nigeria government composed a few zones as grazing routes. However, this has not lessened conflicts. From 1996 to 2006 around 121 persons lost their lives in Bauchi and Gombe states because of contentions amongst pastoralists and ranchers. Mayah (2016) report 
that 300 villagers were reportedly massacred in the killing spree with heavy casualties recorded in communities like Aila, Okokolo, Akwu, Adagbo, Odugbehon and Odejo. Also, on the March 5th, 2016 the rampaging herdsmen killed about 500 people following an attack on Agatu local government region of Benue state. These people groups incorporate; Aila, Akwu, Adagbo, Okokolo, Ugboju, Odugbeho, Ogbaulu, Egba, and Obagaji. April twelfth, 2016: Fulani herders assaulted two towns in Gashaka Local Government Area of Taraba state on and murdered 15 individuals, April nineteenth, 2016: Twenty-five local government territories in Delta State grounded exercises on the Benin-Asaba Expressway.

They reported that the herdsmen purportedly murdered more than 23 people. noticeably, the police recuperated 20 AK-47 rifles, 70 Dane weapons, 30 twofold barrel firearms and more than 1,000 live ammo, for the most part from Fulani herders amid this period, April 21st, 2016: Farmers in Lagun, Iyana Offa, Offa, Atagba, Lapata and their encompassing networks in Lagelu Local Council Area of Ibadan, Oyo State, charged that a gathering of Fulani equipped men assaulted their networks during the evening, harmed a protect and trucked away assets, April 25th, 2016: Fulani herders assault seven towns in Nimbo in Uzo-Uwani Local Government Area of Enugu State. Around 40 people were supposedly executed, June sixteenth, 2016: Gunmen shotted a 45-year-old renowned farmer suspected to be Fulani herdsmen in Ossissa community in Ndokwa East local government area of Delta state, and June 20th, 2016: At Least 59 Deaths have been recorded following recent attacks on Benue communities such as Ugondo, Turan, Gabo Nenzev - in the Logo Local Government Area by Suspected Herdsmen. This was reported through social media collaboration. The study, therefore, concluded that median social collaboration vs. Facebook, WhatsApp and Twitter can help cub herdsmen-farmers' conflicts in Enugu state, Nigeria.

Recommendations: The study recommended that government and ecologically concerned agencies should employ social media like the Facebook group chats for collaboration and management of herdsmen-farmers' conflicts in Enugu state, Nigeria. WhatsApp group chats should also be used collaboration and management of herdsmen-farmers' conflicts in Enugu state, Nigeria. Twitter group chats should also be used for collaboration and management of herdsmen-farmers' conflicts in Enugu state, Nigeria. However, Users of LinkedIn group chats should use it for collaboration and management of herdsmen-farmers' conflicts in Enugu state, Nigeria. Moreover, users of 2go group chats should as well use it for collaboration and management of herdsmenfarmers' conflicts in Enugu state, Nigeria. The media should cease from advancing biased generalizations about gatherings and people through specific detailing not bolstered by statistical data points. The media should interface more with all intrigue gatherings, people, and stakeholders, so no feeling or intrigue is underestimated. The media, in general, should be pluralistic and mirror the assorted variety of their general public, offering access to different perspectives and the privilege to answer. Likewise, the media, as the principal partner and purveyor of data, should add to the upkeep of peace and compromise in the nation by revealing clashes and emergencies inside the setting of the Code of Ethics in light of believable, genuine, adjusted and objective reporting.

\section{References}

Abbass, I. M. (2001). No Retreat no Surrender Conflict for Survival between Fulani Pastoralists and Farmers in Northern Nigeria. European Scientific Journal, 8(1), 1857-7881.

Adebayo, A. G. (1995). Of Man and Cattle: A Reconsideration of the Tradition of Origin of Pastoral Fulani of Nigeria. History of Africa, 18, 1-21.

Baden, R., Bender, A., Spring, N., Bhattacharjee, B. \& Starin, D. (2009). Persona: An Online Social Network with User-Defined Privacy. University of Maryland.

Best, M. (2013b). Emerging markets peacebuilding in a networked world. Communications of the ACM, 56 (4), 30-32.

Carr, D. F. \& Ebrary, I. (2014). Social Collaboration for Dummies (1st ed.). Hoboken, Conference, and Managing Conflict: When Talk and Structure Collide. Society and Natural Resources, 9, 77-91

Coyle, I. \& Meier, P. (2009). New technologies in emergencies and conflicts: The role of information and social networks. United Nation Foundation.

Dolwick, J. S. (2009). The 'Social' and Beyond: Introducing Actor-Network: A Synthesis of the Approach, Conclusions and Recommendations of TEEB. Journal of Economics of Nature. 
Gagliardone, I., Kalemera, A., Kogen, L., Nalwoga, L., Stremlau, N. \& Wairagala, W. (2015). In Search of Local Knowledge on ICTs in Africa. ICTs, State building and Peacebuilding in Africa. Retrieved from http://repository.upenn.edu/africaictresearch/4.

Gray, B. (1989). Collaborating: finding common ground for multiparty problems. Jossey Bass, San Francisco.

Haythornthwaite, C. (2005). Social networks and Internet connectivity effects. Information, Communication, \& Society, 8(2), 125-147.

Hoffmann, J. (2013). UNPEACE Open Knowledge Network Occasional Working Papers No. 1.

Kelly, T. \& Souter, D. (2014). The World Bank, Washington, D.C. http://elibrary.worldbank.org/doi/pdf/10.1596/978-1-4648-0074-0

Kemmis, D. (1990). Community and the Politics of Place. University of Oklahoma Press, Norman.

Keough, H. L. \& Blahna, D. J. (2005). Achieving Integrative, Collaborative Ecosystem Management. Conservation Biology, 20(5), 1373-1382.

Kininmonth, S. \& Bergsten, A. (2015). Closing the collaborative gap: Aligning social and ecological connectivity for better management of interconnected wetlands. AMBIO, 44(1), 138-148.

Lee, K. N. (1993). Compass and Gyroscope: Integrating Science and Politics for the Management: Adaptive, Community-based conservation. Island Press, Washington, D.C.

Mayah, E. (2016). Special report: Inside Agatu killing field: blood on the streets, charred bodies everywhere. Premium times. https://www.premiumtimesng.com/news/headlines/200369-special-report-insideagatu-killing-field-blood-on-the-streets-charred-bodies-everywhere.html.

Meffe, G. K., Nielsen, L. A., Knight, R. L. \& Schenborn, D. A. (2002). Ecosystem Management: Adaptive, Community-Based Conservation. Science for a changing world. Island Press, 1718 Connecticut Avenue NW Suite 300 Washington, DC 20009 USA.

Meredith, R. M. (2014). Social Networking Site Use by Mothers of Young Children. CSCW 2014. Parents and Children Baltimore, MD, USA.

Ndolo, I. E. (2005). Mass media system and the society, Enugu: RhyceKerex Publishers.

Nwosu, I. E. \& Wilson, D. (2004). Communication, mass media, and conflict management in Nigeria. Enugu: ACCE (Nigeria Chapter).

Oatley, N. (2011). Search for Common Ground \& United States Institute of Peace http://cu-csds.org/wpcontent/uploads/2009/10/usip2011vdk.pdf.

Obot, C. (2004). Mass media and conflict management. In Nwosu and Wilson's (Eds) Communication, media and conflict management in Nigeria. Enugu: Prime Targets Limited.

Ojo, E. (2003). The Mass Media and the Challenges of Democratic Values in Nigeria: Possibilities and Limitations. London, SAGE Publications.

Okello, M. A. (2014). Identifying motivators for state-pastoralist dialogue: Exploring the relationships between livestock services, self-organisation and conflict in Nigeria's pastoralist Fulani. Pastoralism.

Okoro, N. \& Diri, C. (2009) Public sphere and civic journalism: A fulcrum for effective political communication in Nigeria. Journal of political economy, Vol. 3 No. 1\&2. Nsukka: Department of political science.

Olsson, P., Schultz, L., Folke, C. \& Hahn, T. (2003). Social networks for ecosystem management: a case study of Kristianstads Vattenrike, Sweden. The Centre for Transdisciplinary Environmental Research (CTM) Stockholm University, SE-106 91 Stockholm, Sweden

Pillay, K., van Niekerk, B. \& Maharaj, M. (2010). Web 2.0 and its implications for the military. In J. Phahlamohlaka, L. Leenen, N. Veerasmay, M. Modise, \& R. van Heerden (Eds.), Workshop on the uses of ICT in warfare and the safeguarding of peace (pp. 50-57). Bela-Bela, South Africa: Council for Scientific Research.

Rathwell, K. J. \& Peterson, G. D. (2012). Connecting Social Networks with Ecosystem Reputation in Social Media: A Dynamic Structural Model. Journal of Management Information Systems, 29, 41-75.

Schoemaker, E. (2013). (WP1278). Media and fragile states. Wilton Park. https://www.wiltonpark.org.uk/wp-content/uploads/WP1278-Report.pdf

Schoemaker, E. \& Stremlau, N. (2014) Media and conflict: An assessment of the evidence. Progress in Development Studies, 14(2), 181-195.

Smyth, T. \& Best, M. L. (2013). Tweet to Trust: Social Media and Elections in West Africa. Presented at the Sixth International Conference on Information and Communication Technologies and Development (ICTD2013), Cape Town, South Africa. 
Tamine, L., Soulier, L., Paris, F., Jabeur, L., Ben, Amblard, F., Cedex, T. \& Roth, C. (2016). Social Media-Based Collaborative Information Access: Analysis of Online Crisis-Related Twitter Conversations. Halifax, NS, Canada, 16, 159-168. Social Anthropology, 3(2), 451-459.

Tang, Q., GU, B. \& Whinston, A. B. (2012). Content Contribution for Revenue Sharing and Reputation in Social Media: A Dynamic Structural Model. Journal of Management Information Systems, 29 (2), 41-76.

TEEB. (2010). The Economics of Ecosystems and Biodiversity: Mainstreaming the Services for Watershed Governance: A Social-Ecological Network Perspective Highlights the Critical Role of Bridging Organizations. Ecology and Society, 17(2).

Ushahidi. (2012). Deployments. Retrieved from http://community.ushahidi.com/deployments

USIP. (2011). The Impact of New Media on Peacebuilding and Conflict Management. United States institutes for Peace. https://www.usip.org/publications/2011/09/impact-new-media-peacebuilding-andconflict-management

Vinson, J. (2011). Social networks become preferred lines of communication during Japan earthquake.WebProNews.com. Retrieved on October 30, 2016 from http://www.webpronews.com/japan-earthquake-social-networkin-2011-03

Walker, G. B. \& Daniels, S. E. (1996). The Clinton administration, the Northwest Forest Conference, and conflict management: when talk and structure collide. Society and Natural Resources, 9, 77-91.

Welch, J. R. Halford, S. \& Weal, M. (2015). Conceptualizing the web for post-conflict governance building. Peacebuilding, 3(1), 58-74.

World Bank. (2009). Convenient Solutions to an Inconvenient Truth: Ecosystem-based Approaches to Climate Change. Environment Department. The World Bank. 